\section{Enabling disabled people to plan personalised assistance}

The WelcoMe App enables patients with a disability to plan personalised assistance when they visit a dental practice.

The London Centre for Cosmetic Dentistry is the first dental practice in the UK to install this technology.

Using the app, disabled patients build and share an accessibility profile and can inform the practice when they are attending and their specific needs.

Once they are en route, the practice can track where the user is and be at the door ready to welcome and assist where necessary.

WelcoMe businesses receive real time training and clear guidance on how to interact with customers directly related to their needs, disabilities or conditions they disclose and in return disabled visitors are provided with key up to date accessibility and assistance information. The WelcoMe app is supported by leading charities, such as RNIB, Alzheimer's Society and Deafblind UK, and caters for a wide range of disabilities, including deafness, autism, dementia, visual impairment and stammering.

For more information on WelcoMe visit www.wel-co.me, email caro@ wel-co.me or call 07449451325.

\section{One platform, smart prosthetics}

NeossONE is a solution unique to the Neoss Implant System - one prosthetic platform, across three implant ranges, including ALL implant diameters and abutments.

Simply put, the same prosthetic components fit every implant [narrow diameter implant range excluded].

One prosthetic platform, across three implant ranges, means one impression coping, one implant replica and one abutment interface, facilitating treatments that are adaptable and versatile. With fewer components in the system, complexity is reduced and time-efficiency is improved. All of which results in a truly cost-effective solution and predicable outcome.

In contrast to traditional implant systems necessitating up to 1,000 components, Neoss uses a minimum number of components to achieve the highest level of flexibility and functionality, without compromise. Using NeossONE, with its proven long-term clinical performance, enables integration of innovations in surgery and prosthetic rehabilitation, providing unique benefits for the whole dental team. For clinicians, it means predictable aesthetics, soft tissue integration and prosthetic precision. The ingenuity lies not only in the NeossONE solution, but in the patented Neoss implant design that optimises stability in all bone qualities and conditions and eliminates the need for separate one- or two-stage designs. The benefits of both are clear: a predictable solution with shorter chair time and optimised inventory control.

Visit https://www.neoss.com/en/ products-solutions/neossone or email info@neoss.com.

\title{
Achieve perfect clarity as you work
}

The Carl Zeiss EyeMag Light II dental loupes deliver coaxial, daylight-quality illumination that is evenly distributed across the entire treatment site for a clear, unaltered view of tiny details and structures, with minimal shadow formation. It comes complete with two rechargeable battery packs that each offer up to eight hours of operation for a virtually interruption-free workflow.

With a swing-in image filter that prevents premature curing of composite materials, the EyeMag Light II is a must-have solution for your restorative armamentarium.

For more information call Nuview on 01453 872266, email info@nuview-ltd.com or visit www.nuview.co.uk.

\section{All-in-one medical 3D printer}

Stratasys Ltd. has introduced a medical 3D printer that sets a new standard for healthcare providers and medical device companies by combining multiple applications in one system. With multiple materials and multi-colour capabilities, the Stratasys J5 MediJet 3D printer enables users to create highly detailed 3D anatomical models and drilling and cutting guides with approved third-party 510k-cleared segmentation software. Guides and models are certified as sterilisable and biocompatible, and the printer is economical and compact enough for small lab spaces.

The J5 MediJet 3D printer is the newest addition to the Stratasys J5 Series of printers, along with the J5 DentaJet and J55. In operation, it features a patented rotating build platform with a fixed print head. This is designed to maximise reliability and simplify maintenance. The system also delivers more output from a small footprint. Compared to other 3D printers, the MediJet 3D printer is up to 30\% faster, along with a simple workflow that includes automatic build tray arrangement, corrections and support for the latest $3 \mathrm{MF}$ file format for simplifying connectivity to third-party segmentation and design software.

The new printer supports DraftWhite material for affordable single-material applications, along with a full array of new flexible, rigid colour, and transparent materials. The multi-materials capabilities support a broad range of medical modelling applications in one office-friendly platform, which reduces outsourcing costs or the need for multiple printers.

The printer and materials are available now. Learn more about the clinical and economic value of medical 3D printing on the Stratasys website: https://www.stratasys.com/3d-printers/j5-medijet.

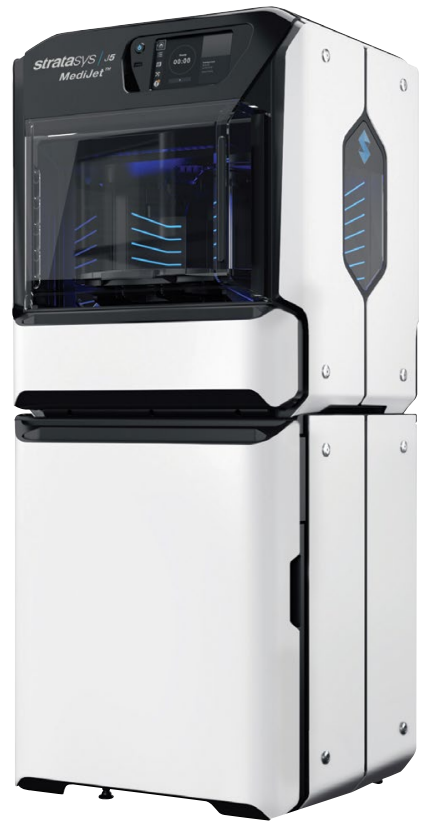

